\title{
LA CARTOGRAFÍA EN LA OBRA DE JAUME VICENS VIVES
}

\author{
POR \\ JOSÉ LUIS VILLANOVA
}

\section{Introducción}

La figura de Jaume Vicens Vives (1910-1960) y su enorme labor desarrollada en los ámbitos de la historia y la historiografía españolas han sido, y continúan siendo, analizadas en numerosos estudios y artículos. En este sentido, y a modo de ejemplo, pueden citarse las colaboraciones realizadas por J. Fuster, J. Mercader, J. Reglà, J. Rubió, F. Soldevila y J. Trueta, entre otros, en el n. ${ }^{\circ} 11$ de Serra d'Or (1960), con motivo de su fallecimiento; los volúmenes del Homenaje a Jaime Vicens Vives (1965) —en el primero de los cuales se incluye una completa bibliografía de su obra, realizada por P. Galera-; la aportación de R. Grau y M. López (1979) en Ictineu. Diccionari de les Ciències de la Societat als Països Catalans (s. XVIII-XX); los artículos de S. Riera, B. de Riquer o E. Serra aparecidos en el n. ${ }^{\circ} 83$ de Avenc — publicado con motivo del $25 .^{\circ}$ aniversario de su muerte-; el volumen Epistolari de Jaume Vicens de J. Clarà et alii (1944) que cotiene una selección representativa de su correspondencia privada; o, más recientemente, la excelente tesis doctoral de J. M. Muñoz, defendida en 1995 y publicada en 1997.

Si bien es cierto que la inmensa mayor parte de la actividad desarrollada por Vicens se centró en los mencionados campos, hay que su-

José Luis Villanova: Departamento de Geografía, Historia e Historia del Arte. Universidad de Gerona.

Estudios Geográficos

Tomo LIX, n. ${ }^{\circ} 233$, octubre-diciembre 
brayar que realizó interesantes aportaciones en los ámbitos de la geografía y de la geopolítica. Sus trabajos en estas líneas también han merecido la atención de diversos especialistas: D. Batallé y J. M. Rabella (1978), J. Bosque Maurel et alii (1984), A. T. Reguera (1991), J. L. Villanova (1995) o A. Fabre y J. L. Villanova (1997).

El principal objetivo de este artículo es efectuar un análisis introductorio de sus aportaciones e ideas respecto de la cartografía, aspecto al que Vicens otorgó una extraordinaria importancia en todos sus trabajos y que, si bien ha sido abordado parcialmente en algunos de los ensayos recién citados, hasta el momento no ha sido tratado específicamente ${ }^{1}$. Concretamente se examina su aportación cartográfica en los ámbitos de la historia, la geografía y, fundamentalmente, la geopolítica; así como en el conjunto de sus obras destinadas a la enseñanza secundaria.

El artículo comprende el análisis de los rasgos cartográficos más importantes que impregnan la obra de Vicens; el origen de sus fuentes; la estructura que presentan sus obras más significativas en este ámbito, sus principales planteamientos y el papel que otorgó a la cartografía en el conjunto de su obra. Podría haberse optado por centrarse en profundidad en el contenido y estructura de los mapas que se incluyen en alguna de sus numerosas obras, pero el hecho de que hasta el momento no se haya abordado en conjunto el examen de su obra cartográfica, en ningún trabajo específico, motivó la elección que se ha señalado. Por otro lado, hay que indicar que tampoco se realiza un estudio detenido sobre los contenidos de sus obras, pues no es éste el objetivo del artículo y para ello pueden consultarse los ensayos ya reseñados.

El primer apartado se dedica a valorar, someramente, el papel de la cartografía en las obras de Vicens, sus concepciones al respecto, las razones de su interés por ella, el origen de dicho interés, sus primeras incursiones y las orientaciones que proporciona para la elaboración de los atlas históricos.

A continuación se analiza el papel de la cartografía en sus obras destinadas a la enseñanza secundaria, tomando como hilo conductor alguno de sus manuales editados por Teide y, principalmente, el Atlas de Historia de España y el Atlas de Historia Universal.

${ }^{1}$ Este artículo tiene su origen en un trabajo presentado, para su evaluación, en el Curso «Introducció a la història de la Cartografia. VIII» del «Programa de Doctorat en Geografia Humana (curs 1996-1997) organizado por la Universitat Autònoma de Barcelona. 
El tercer apartado se consagra al estudio de la cartografía geopolítica que Vicens incluyó en sus artículos publicados en el semanario Destino, en su mayor parte entre 1939 y 1940, y, especialmente, en España. Geopolítica del Estado y del Imperio (1940) y Tratado General de Geopolítica (1950). Aunque en los dos primeros apartados se realizan algunos comentarios acerca de las concepciones de Vicens sobre la geopolítica y sus técnicas cartográficas - las cuales impregnaron muchos de sus trabajos-, se ha decidido dejar este aspecto para el final, por considerarlo el más importante y poder ofrecer, de este modo, una perspectiva más globalizadora y comprensiva del tema.

Los materiales consultados se han localizado en la Hemeroteca general de la Universitat Autònoma de Barcelona, la Biblioteca de Catalunya, la Biblioteca de la Facultat de Lletres de la Universitat de Girona y la Biblioteca personal de Jaume Vicens Vives ${ }^{2}$. Los atlas históricos publicados por Vicens en Teide, así como otras obras destinadas a la enseñanza secundaria que han sido utilizadas, fueron proporcionados por Anna Fabre.

\section{Jaume Vicens Vives y la cartografía}

El conjunto de la obra de Vicens, tanto histórica como geográfica, incluye abundantes mapas y gráficos cartográficos. A lo largo de toda su vida, el eminente historiador, mostró un vivo interés por interrelacionar en sus estudios geografía, historia y cartografía. Para él, la cartografía no sólo servía para situar y confrontar acontecimientos históricos, también permitía valorar correctamente la importancia y significación de los hechos geográficos y su influencia en los acontecimientos históricos. Pero además, el protagonismo que adquirió la cartografía en el conjunto de su obra se acentuó en sus trabajos geopolíticos. En este sentido puede afirmarse que es un elemento clave integrado en su obra. Como señalan Batallé y Rabella (p. 283) podría «ser considerada como elemento clave para entender la unidad de la obra de nuestro autor. Historia, Geografía y Geopolítica quedan así más ligadas por esta necesidad de grafiar, situar y relacionar el espacio en cualquier hecho estudiado».

${ }^{2}$ La Biblioteca personal de Jaume Vicens Vives fue cedida, en depósito, por su viuda a la Universitat de Girona en 1988. Actualmente se ubica en la Facultat de Lletres de esta universidad. 
Su interés por la cartografía se despertó a principios de los años treinta, recién finalizados su estudios universitarios, cuando leyó el volumen La Terre et l'évolution humaine de L. Febvre. Sobre el mismo, Vicens escribió: «La lectura del libro me sobrecogió... Quizá mi afición a lo geopolítico y a lo geohistórico, mi inveterada afición a confabular hombre y espacio, a buscar la realidad histórica en la cartografía, provenga de aquella fructuosa lectura» (Vicens, 1951, p. 14). A esto hay que añadir el hecho de que en 1932, en la Biblioteca de la Universidad de Barcelona, descubrió un número de la revista Zeitschrift für Geopolitik -órgano de expresión de la escuela alemana de geopolítica-, el cual excitó su atracción por esta disciplina (Vicens, 1950, p. 6). Acerca de la importancia de la cartografía en la geoploítica, son esclarecedoras las palabras del propio Vicens: «La Geopolítica desempeña su cometido a través del mapa y del gráfico... Todo fenómeno geopolítico que no tenga una traducción directa sobre el gráfico, o escapa a las leyes de esta ciencia y por consiguiente es un elemento perturbador de la misma, o pierde casi todo valor en consideración y en trascendencia efectiva» (Vicens, 1940, p. 23). En este sentido puede destacarse la gran labor desempeñada por Vicens al introducir en España los principios y técnicas cartográficas que habían sido ampliamente desarrolladas por la escuela alemana de geopolítica.

Dos factores pueden considerarse claves para explicar su preocupación por la cartografía: la utilidad e importancia que otorgaba a la geopolítica — de la que el mapa es componente indisoluble-y su enorme vocación didáctica.

Vicens siempre estuvo interesado por todo lo que le rodeaba y siempre se esforzó por hacer comprensible los acontecimientos históricos y contemporáneos a sus semejantes, para que éstos pudieran desarrollarse de manera más humana, crítica y consciente. Al respecto consideraba que la geopolítica «es de suma utilidad para la correcta información del ciudadano e imprescindible para cuantos intervienen en la orientación exterior de la vida de una colectividad humana» (Vicens, 1950, p. 7).

Por otro lado, concedió a la cartografía un papel fundamental en todas sus obras destinadas a la enseñanza secundaria al considerarla inseparable de la cartografía y de la historia. En relación a la primera, en el «Pórtico» del Atlas Iberoamericano de Geografía Mundial planteaba: «No se puede profundizar en el estudio de la Geografía sin complementarlo con el de otras ciencias: Astronomía, Geología, Cartografía, So- 
ciología, Economía, Demografía, Urbanismo. De todas ellas, la Cartografía es el elemento básico. Apoyándose en una buena labor cartográfica, se puede llegar a un conocimiento profundo de todos los aspectos de un continente, de un país o de una región» ${ }^{3}$. Respecto a su vinculación con la historia, en el «Pròleg» de Històra. Primeres lectures - publicado conjuntamente con Enric Bagué, en 1936-, aconsejaba a los jóvenes lectores: «Acostumbraos a buscar en los mapas que encontraréis en este libro las tierras, los reinos y los itinerarios que vayáis leyendo. Estos mapas no ilustran sólamente el capítulo en el que se encuentran incluidos, sino que os servirán también para situar los lugares geográficos, los imperios, las invasiones, etc... Es posible que algunos de los lugares o tierras citados no los encontréis en estos mapas... recordad que existen los Atlas geográficos y los Atlas históricos...» ${ }^{4}$.

Otras de sus primeras incursiones en el campo de la cartografía - además de la recién mencionada - se produjo durante la Guerra Civil. Carles Pi i Sunyer - Conseller del Departament de Cultura de la Generalitat de Catalunya - le encargó, junto a Alexandre Cirici, la realización de un libro en el que sería presentada de forma visualizada la historia de Cataluña, con la intención de aprovecharlo también en favor de la concienciación del pueblo catalán. Según Cirici, el trabajo se organizó del siguiente modo: «Vicens hacía unos textos cortos de cada etapa y yo meditaba la manera de visualizar la historia en términos de núcleos, intensidades, trayectorias, frentes, ejes, etc.» (Cirici, p. 216). El volumen se acabó los últimos días de 1938 (Ibid.), pero la aproximación y entrada de las tropas franquistas en Barcelona impidió su publicación, perdiéndose los originales y sin que sobreviviera ninguna copia ${ }^{5}$.

A pesar de esta lamentable pérdida los contenidos de esta obra no se malograron completamente. Cirici comenta que, tras la Guerra Civil, Vicens «amplió los textos, los tradujo (al castellano), les añadió otro

\footnotetext{
${ }^{3}$ Citado en Batallé y Rabella, p. 283.

4 Citado por Anna Fabre en el Seminario «Jaume Vicens Vives», celebrado el 28 de abril de 1995, en la Facultat de Lletres de la Universitat Autònoma de Barcelona, dentro del curso de doctorado Grans mestres de la geografia catalana al segle XX.

${ }_{5}$ No existe unanimidad acerca del lugar donde desaparecieron los originales. Cirici manifiesta que se debieron perder en el Palau Robert, sede del Gobierno de la Generalitat en Barcelona (Cirici, p. 217), mientras que Joseph i Mayol asegura que llevó las últimas pruebas corregidas al taller de los hermanos Oliva en Vilanova (Barcelona) para su impresión, el 21 de enero de 1939. La paralización de todas las actividades el día 23, a consecuencia de la proximidad del ejercito franquista, y la posible fundición posterior del plomo, debieron provocar su desaparición (Joseph i Mayol, pp. 147-148).
} 
contenido y los convirtió en un libro que tituló Geopolítica de España y del Imperio (sic.). Su cuñado, Josep Rahola, por entonces estudiante de ingeniería, que sabía dibujar, reconstruyó mis mapas perdidos, guiado por la buena memoria visual de Vicens» (op. cit., p. 217). Con este volumen -España. Geopolítica del Estado y del Imperio (1940)—, Vicens quiso resaltar el valor pedagógico de divulgación de la geopolítica y en él aplicó - al igual que en el anterior- los principios básicos y técnicas cartográficas de la escuela alemana de geopolítica. Pero no deja de ser ciertamente paradójico que, mientras la primera obra se diseñó pensando en la concienciación del pueblo catalán durante la Guerra Civil, en esta segunda «versión» se realizara un análisis de la historia de España bajo una óptica marcadamente imperialista. En la misma «realiza concesiones a la ideología dominante y se aprecia una adaptación a la retórica imperial mezclando explicaciones materiales y espirituales del hecho imperial (Fabre y Villanova, p. 93).

El cuidado y la trascendencia con que consideró a la cartografía, además de plasmarse en una gran parte de sus obras, igualmente los puso de manifiesto en el Primer Congreso Internacional de Pireneistas, celebrado en San Sebastián en septiembre de 1950. En el mismo presentó, junto con $\mathrm{Ph}$. Wolff, la comunicación «Principios de un método para la elaboración de los mapas históricos de un atlas pirenaico». La importancia de la preparación de un atlas histórico de los Pirineos radicaba, para ambos autores, en que «para los geógrafos ese Atlas sería un instrumento de primer orden, en cuanto fijaría los principios de la investigación de la Geografía Humana actual; y a los historiadores proporcionaría una visión cartográfica del pasado, científica, apartada de cualquier incorrección por ideologías preconcebidas o defectuoso enfoque de los problemas» (Wolff y Vicens, p. 5).

En dicha comunicación no se limitaban a desarrollar lo que el título indica, sino que también exponían consideraciones metodológicas acerca de la elaboración de los mapas históricos en general: «un mapa histórico no puede limitarse a ser una mera localización cartográfica de los nombres que el historiador lee en los documentos o enumera en sus obras, ni incluso de las fronteras de los Estados o de los Principados... Un Atlas de este tipo debe, ante todo, plantear problemas y suministrar elementos de juicio en vistas a su resolución. Y el primer problema es el del espacio en que los hombres del pasado han actuado, circulado, comerciado y gobernado» (op. cit., pp. 5-6). 
Entre los difíciles problemas, que se deben afrontar en el momento de efectuar una tarea como ésta, señalan: la «representación total» y el «ritmo». La solución del primero pasa por «repudiar la idea de disociar la representación del relieve de la representación de los fenómenos históricos, puesto que éstos sólo pueden alcanzar su significado pleno sobre un fondo cartográfico que indique el relieve» (op. cit., p. 9). Pero al tratarse de mapas históricos, y no estrictamente geográficos, añaden que hay que «aproximarse lo más posible a la realidad del relieve mediante un dibujo que, evocándolo de una manera sencilla, sea ya una abstracción del mismo, así como una explicación intencionada» (Ibid.). Al trabajar bajo estas orientaciones se produce, evidentemente, una simplificación que implica cierta deformación, pero los autores consideran que «ésta es la menos grave de todas». En el momento de elaborar estos mapas, la capacidad de síntesis deviene primordial ${ }^{6}$.

Esta misma capacidad de síntesis debe manifestarse al encarar el problema del «ritmo». El mapa histórico representa la materialización de un conjunto de fenómenos en un momento de mayor o menor amplitud, pero la historia es un continuo ininterrumpido, y no puede ser deformado aislando los instantes principales. Para solucionar este grave inconveniente proponen realizar una tarea previa, «la de elegir los "momentos" más propicios a una buena comprensión cartográfica, en función tanto de los fenómenos históricos como de los datos de que dispongamos, y de relacionar unos con otros mediante indicaciones más someras» (op. cit., p. 10).

\section{La cartografía en su obra educativa}

La Cartografía también ocupó un puesto primordial en el conjunto de la labor educativa de Vicens. Ya durante el curso 1932-33 —en el que ejerció como profesor en el Institut-Escola de Barcelona ${ }^{7}$ - alumnos suyos, como María Aurélia Capmany o Jordi Riba, recuerdan su afición a dibujar abundantes mapas en la pizarra (Muñoz i Lloret, pp. 43-45). La

\footnotetext{
${ }^{6}$ Muñoz señala que la afición de Vicens por la síntesis fue despertada por Pere Bosch i Gimpera, uno de sus maestros durante sus estudios universitarios (pp. 32-33).

${ }^{7}$ Este centro fue creado por la Generalitat de Catalunya en vistas a la estructuración de la enseñanza secundaria y desempeñó un papel destacado en la formación del profesorado de esta etapa educativa.
}

$$
-717-
$$


preocupación por la cartografía en la enseñanza —que igualmente quedó puesta de manifiesto, como se ha comentado, en el «Pròleg» de la obra Història. Primeres Lectures (1936) - sería una de las características que lo harían célebre como profesor desde los primeros momentos.

Pero será a partir de 1942, con la fundación - junto con su cuñado Frederic Rahola- de la editorial Teide, cuando su interés por la cartografía en el ámbito educativo se desarrollará y manifestará plenamente. Puede ser significativo al respecto señalar que la primera producción editorial consistió en una colección de mapas mudos (op cit., p. 134). La creación de Teide «marcará un hito en el mundo editorial dedicado a la enseñanza, por sus planteamientos renovadores y por la importancia capital dada a las ilustraciones (mapas, gráficos, ...)» (Fabre y Villanova, p. 93).

A lo largo de su corta, pero intensa, vida publicó en esta editorial más de una veintena de textos - en los que se incluían abundantes ilustraciones- de Geografía, Historia, Geografía e Historia y Atlas históricos, orientados a la enseñanza secundaria ${ }^{8}$. De ellos, Vicens escribió ocho en solitario y dieciséis más conjuntamente, con autores o colaboradores como L. Pericot, A. del Castillo, S. Sobrequés, J. Bosque Maurel, A. Pla Gibernau, J. Wagner o E. Bagué. De la mayor parte de los mismos se tiraron diversas ediciones - muchas de ellas corregidas y actualizadasdebido al éxito de ventas que alcanzaron.

La cartografía, como señalaba anteriormente, desempeñó un papel fundamental en su obra educativa y Vicens promocionó continuamente el uso de mapas en las actividades escolares. En el Catálogo n. ${ }^{\circ} 2$ de Ediciones Teide (1944), se comentaba «Un buen ciclo de Geografía e Historia no puede desarrollarse sin utilizar un material excelente de Mapas Mudos» (p. 4) ${ }^{9}$. Años más tarde subrayaba —en la «Advertencia Preliminar» de España geográfica. Curso de geografía- la importancia del aprendizaje de la geografía a partir de imágenes, a pesar del coste económico que su inclusión en los manuales comportaba: «no se ha regateado esfuerzo en esta edición para facilitar visualmente el conocimiento de nuestro país. Se ha continuado utilizando excelente material fotográfico, y al mismo tiempo no se ha vacilado acudir al color para poner de relieve esquemas de geografía económica y física y mapas re-

\footnotetext{
${ }^{8}$ Para una información bibliográfica detallada sobre sus obras destinadas a la enseñanza véase Galera, pp. XXXIII-XXXV.

${ }^{9}$ Citado por Batallé y Rabella, p. 283.
} 
gionales. Esperamos que, de este modo, nuestra labor continuará marcando una huella en la didáctica española y será punta de lanza en su continuo progreso» (Vicens y Sobrequés, p. s. n.).

A modo ilustrativo, efectuaremos una breve descripción de dos de sus obras destinadas al mundo educativo: el Atlas de historia de España y el Atlas de historia universal. La elección de las mismas viene determinada por su propio carácter, el cual encaja perfectamente en un estudio en el que se abordan la importancia y el alcance de las aportaciones cartográficas de Vicens.

Ambas obras fueron publicadas, inicialmente, en 1944 la relativa a la historia de España - bajo el título Atlas y síntesis de historia de España-y en 1945 la correspondiente a la historia universal —atlas y síntesis de historia universal. Sus sucesivos agotamientos originaron numerosas reediciones, en diversas ocasiones corregidas, actualizadas y ampliadas. A partir de 1953 se publicaron en color, con el nuevo título indicado anteriormente, y con doce nuevos mapas inéditos. La tercera edición del segundo (1957) incluyó otras dieciséis cartas originales. El éxito de ventas explica que, en 1973, el primero alcanzara la octava edición, y el segundo, en 1982, la decimoséptima.

Los dos atlas presentan la misma estructura formal: el cuerpo principal lo compone una serie de mapas explicativos de diferentes momentos y períodos de la historia de España y mundial, respectivamente; un apéndice en el que Vicens explica brevemente cada uno de los mapas; y un segundo apéndice, que contiene cuadros sinópticos y series dinásticas, elaborado por J. García Tolsà, E. Ripoll y R. Ortega —éste último sólamente colabora en el relativo a la historia de España. Los dibujantes y cartógrafos fueron, en ambos casos, J. Brun Margalef y R. Rodríguez Arroyo.

El Atlas de Historia de España contiene 83 mapas distribuidos en 62 láminas. Más de la tercera parte de los mismos - concretamente 30proceden del volumen España. Geopolítica del..., publicado en 1940, aunque en esta obra se editaron en blanco y negro (véase Figs. 1 y 2). Unicamente en 14 de ellos —algo menos del $20 \%$ - no se incluyen signos de carácter geopolítico. La importancia de la expresión cartográfica geopolítica era subrayada por Vicens en 1950, cuando escribe que la misma «da plasticidad a las ideas y las hace competir directamente al lector en un despliegue de eficacia pedagógica» (Vicens, 1950, p. 78). 


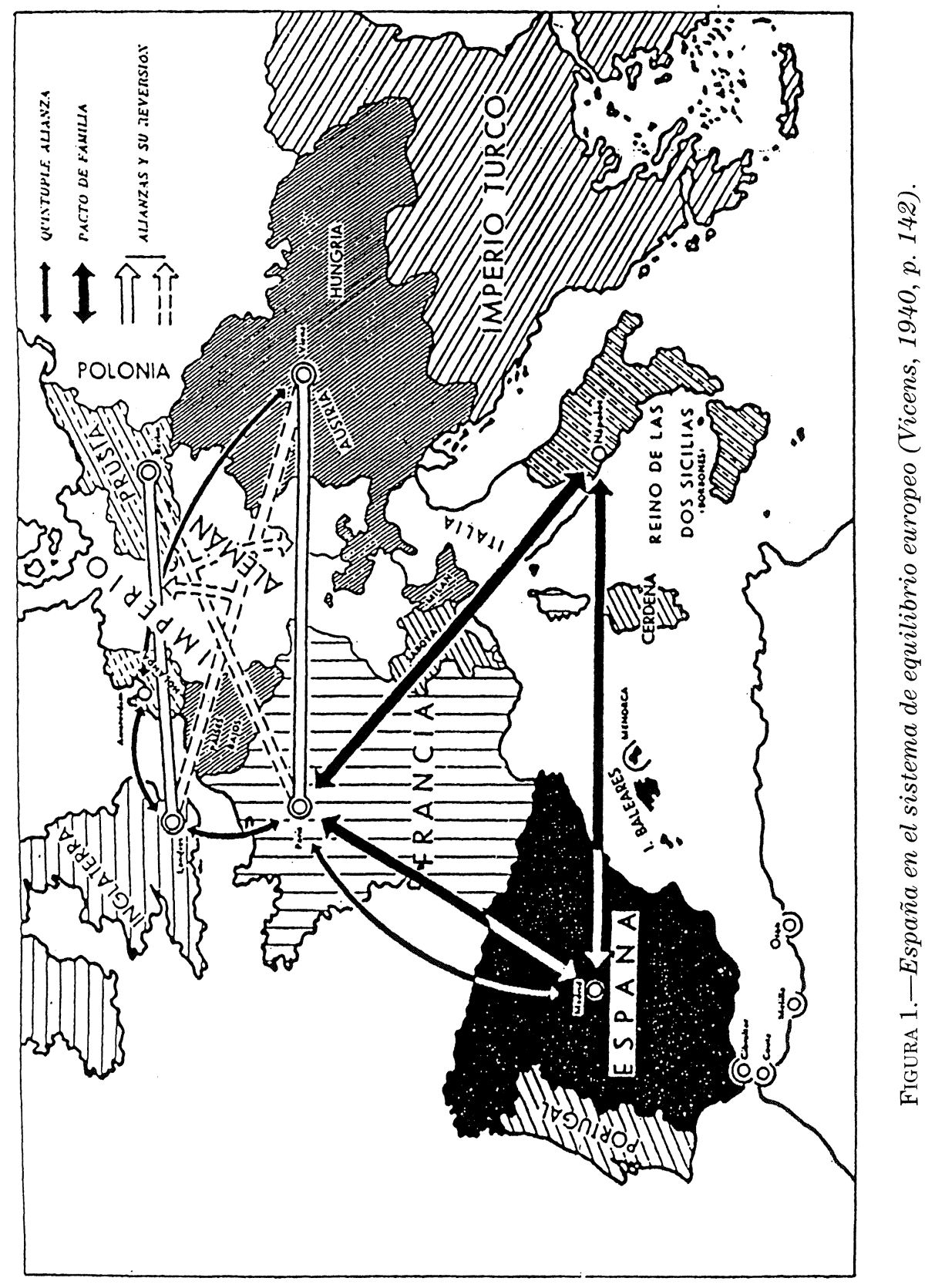




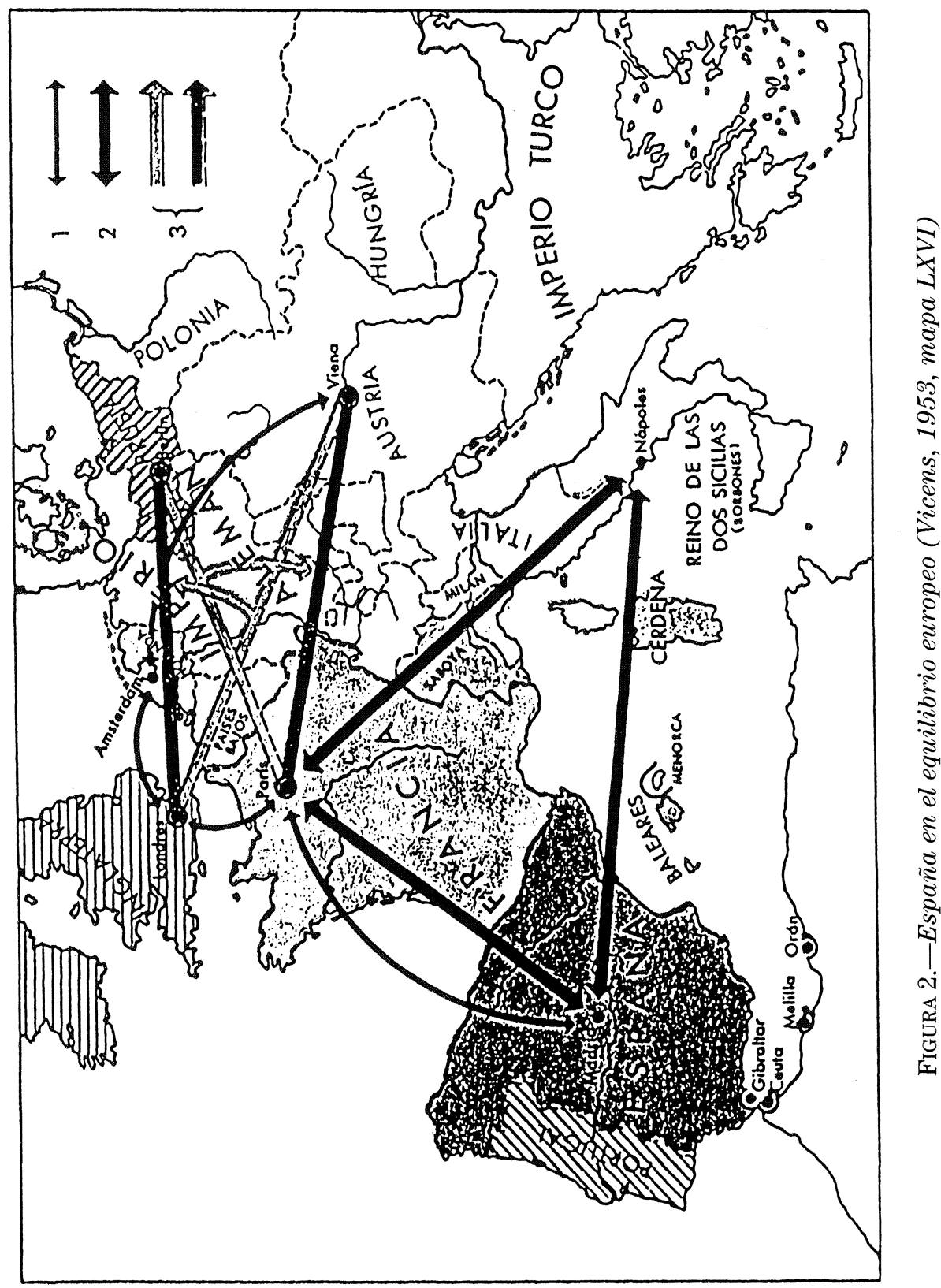


Por su parte el Atlas de Historia Universal incluye 90 mapas repartidos en 70 láminas. Sólamente 7 de ellos proceden de España. Geopolítica del... y 18 también se incluyen en el otro atlas mencionada. En este volumen, la ausencia de imágenes con signos geopolíticos es más notoria que en el caso anterior, y son 32 los mapas que no recogen este tipo de simbología.

\section{La cartografía geopolítica}

Vicens manifestó a lo largo de su vida un gran interés por la geopolítica y para algunos fue el «único científico español a quien el tema preocupó tanto conceptual como empíricamente» (Bosque Maurel et alii, p. 47). Sobre las motivaciones que le indujeron a incidir en este campo, Reguera apunta que «el motivo principal» fue «el de examinar las posibilidades científicas de la geopolítica, así como su proyección ideológica y política» (p. 20). No obstante, y a partir de la lectura de algunas de sus afirmaciones - v. p. 4-, puede añadirse que éste no fue el único motivo. Vicens, que consideraba a la geopolítica como una disciplina muy útil para los ciudadanos, y especialmente para los políticos, también profundizó en su estudio y la difundió con la finalidad de favorecer el desarrollo consciente, crítico y activo de sus semejantes.

Ademas de los mapas que incluyó en las diversas obras ya comentadas, Vicens presentó su más variado repertorio de técnicas cartográficas geopolíticas, y sus planteamientos al respecto, en sus dos «grandes» obras referidas a esta disciplina: España. Geopolítica del Estado y del Imperio (1940) y Tratado General de Geopolítica (1950). Por otra parte, entre julio de 1939 y septiembre de 1940, publicó en el semanario Destino ${ }^{10} 28$ artículos ${ }^{11}$ de carácter geopolítico, con finalidades divulgativas.

Finalizada la Guerra Civil, Vicens pasó por un período en el que pa-

${ }^{10}$ Esta revista había sido fundada en Burgos, en 1937, por un grupo de intelectuales catalanes que militaban en el bando franquista. Entre ellos se encontraban X. de Salas y J. M. Fontana, a los que posteriormente se sumarían I. Agustí, J. Vergés y J. R. Masoliver. A los pocos meses de finalizar la guerra, la revista se publicó en Barcelona. Si bien pasado un tiempo adquirió una orientación más liberal y moderadamente catalanista, los primeros años fueron de claro predominio falangista.

${ }_{11}$ Para una completa información bibliográfica sobre los mismos, consultar Galera, pp. XXVI-XXVIII. 
deció ciertas dificultades económicas, pues había sido apartado de su puesto de profesor en la Universidad de Barcelona por razones políticas. Posiblemente con la intención, en parte, de paliar esta situación publicó dichos artículos.

El primero de ellos — «Teoría del "espacio vital"», (15-7-1939)— lo firmó con su propio nombre y el resto bajo el seudónimo de Lorenzo Guillén. En los mismos realizaba comentarios geopolíticos, con finalidad pedagógica, sobre diferentes zonas del planeta afectadas por las operaciones de la II Guerra Mundial; denunciaba, con el lenguaje anticomunista característico del momento, la política «expansionista» de la Unión Soviética; elogiando la política exterior de los regímenes fascistas; criticaba la intención de Estados Unidos de convertir el Caribe en un mar norteamericano y reclamaba un nuevo papel para España en el nuevo orden mundial. Los artículos, indudablemente sujetos a la férrea censura de aquellos años, iban acompañados de mapas geopolíticos que ilustraban gráficamente los análisis expuestos (véase Fig. 3).

En estos artículos, aunque utilizó las técnicas cartográficas geopolíticas que ya conocía perfectamente, no realizó comentarios acerca de su utilidad, valor e importancia, seguramente a causa de su carácter eminentemente divulgativo. Sus planteamientos en relación al tema quedaron plasmados esencialmente en los dos volúmenes anteriores citados.

Vicens consideraba que la geopolítica comportaba un gran valor pedagógico gracias, sobre todo, a sus técnicas cartográficas, ya que «la representación plástica de los hechos históricos fundamentales...[es] base eficiente y primordial de comprensión y enseñanza» (Vicens, 1940, p. 26). Apoyándose en dichas técnicas - y con la «finalidad estricta» de «dar a conocer a la juventud y el pueblo de España los rasgos geopolíticos más sobresalientes de su ser histórico y contemporáneo como escabel de sus manifestaciones venideras» (op cit., p. 25)- decidió publicar en 1940 España. Geopolítica del..., aprovechando materiales que había preparado anteriormente - v. p. 6-.

En este volumen realiza un análisis de la historia de España bajo una óptica marcadamente imperialista, aplicando las técnicas cartográficas de la escuela alemana de geopolítica. La obra consta de un cuerpo central de 90 mapas geopolíticos, acompañados de una breve explicación. «Deslumbrado» por las aportaciones cartográficas de la escuela alemana de geopolítica, no dudará en utilizar, como base, algunos mapas elaborados por miembros de dicha escuela en este volumen (véase Figs. 4 y 5). 


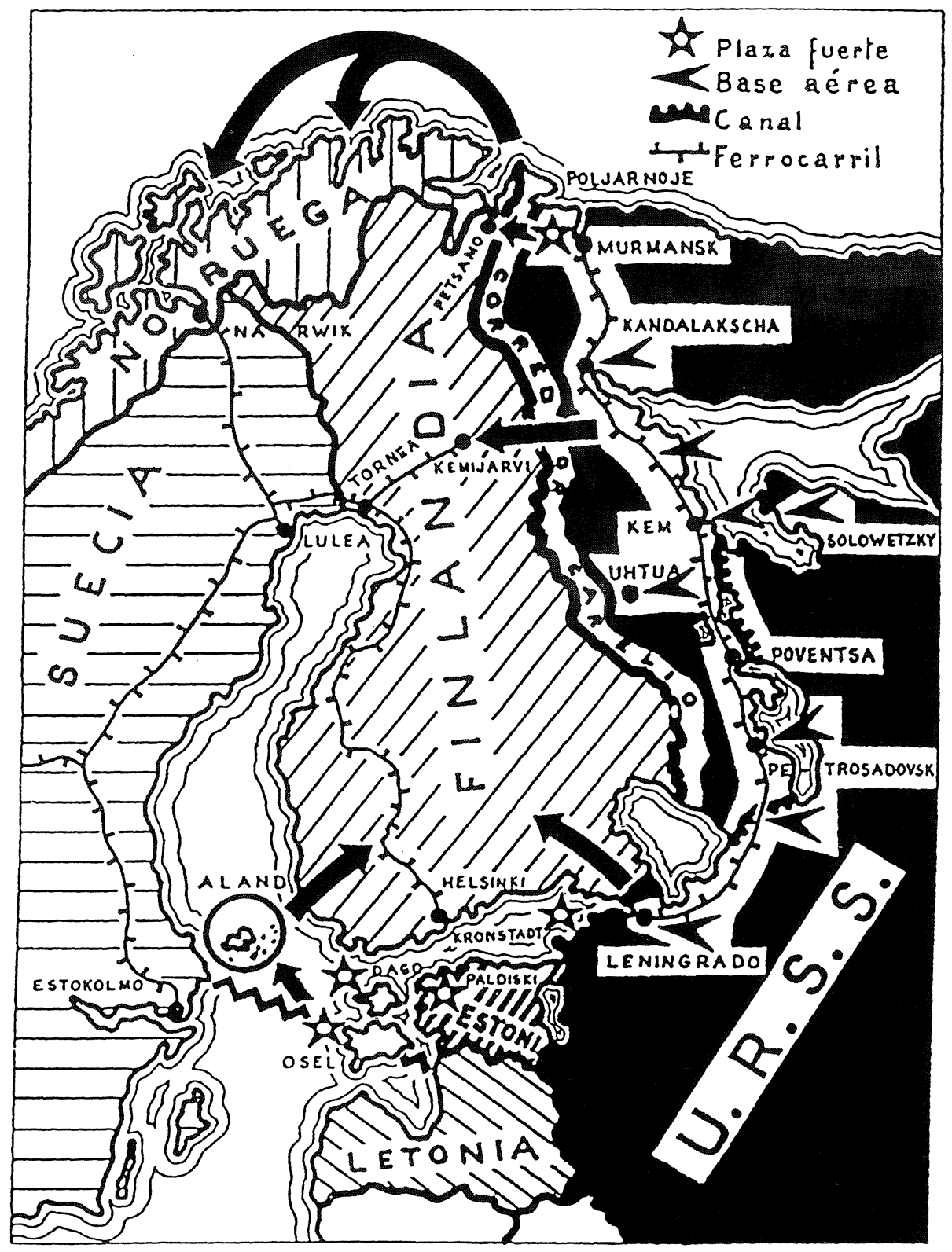

FIGURA 3.-La expansión soviética en el Báltico (Vicens, 1939). «Presentamos un gráfíco de la expansión soviética en el Báltico, indicada por la dirección de las flechas. La Rusia actual pretende dominar todo el norte del mar y abrirse paso hacia el Océano. Busca con ello la salida a Europa, ideal constante de su imperiualismo».

$$
-724-
$$


La estructura formal de la obra es idéntica a la que diseñó Horrabin para su An Atlas of Current Affairs (1934), el cual era conocido perfectamente por Vicens, pues poseía un ejemplar del mismo. Este núcleo central viene precedido por una amplia «Introducción a la Geopolítica», de 28 páginas, en la que expone los principios de esta disciplina, su importancia y utilidad, y de manera bastante extensa sus planteamientos acerca de las técnicas cartográficas geopolíticas.

Con anterioridad se ha comentado la importancia y la utilidad que Vicens otorgaba a este tipo de cartografía. Aquí nos detendremos a analizar las ideas que manifiesta el autor sobre cuáles deben ser las características que los mapas geopolíticos deben reunir, los peligros que conllevan y cuáles son los principales signos geopolíticos que en ellos se incluyen.

Para Vicens, «los mapas geopolíticos han de tener una calidad esencial: ser sugestivos» (op. cit., p. 23). Pero también era consciente que la capacidad de «sugestión» que conllevan estos mapas - proporcionada por «signos» geopolíticos, que invitan a comprender el desarrollo de los fenómenos históricos y culturales que se localizan en el espacio terrestre- encierra uno de los grandes peligros que pueden provocar los mismos. Ante ello propone «moderación y severo control en el uso del símbolo geopolítico y realzar su carácter científico» (Fabre y Villanova, p. 99). En defensa de su utilización científica, argumenta que en Alemania, donde la tergiversación de los mapas geopolíticos efectuada por los nazis había alcanzado su culminación, A. Hillen Ziegfeld «uno de los autores que ha tenido una participación más activa en la caracterización y divulgación de este tipo de gráficos» (Vicens, 1940, p. 23) - «hubo de protestar, en 1935 en un artículo "La representación cartográfica - ¿un deporte o un arma?-_, el diletantismo que atacaba la educación política del pueblo alemán» (op. cit., pp. 23-24).

En esa línea, reivindica su uso científico y recuerda la definición que de los signos geopolíticos realizó Ruppert von Schumacher - teorizador de los mismos, según el propio Vicens-: «símbolos que se dan en la zona de los acontecimientos políticos abstractos (impulsos espirituales, ideas y sentimientos) o reales (tendencias y hechos objetivos, cuando pueden recibir una significación geopolítica abstracta). Todo signo ha de reunir tres posibilidades: cartográfica, gráfica y psicológica, ésta última muy interesante, ya que tiene en cuenta el nivel cultural del pueblo al que se destina» (op. cit., p. 24). 


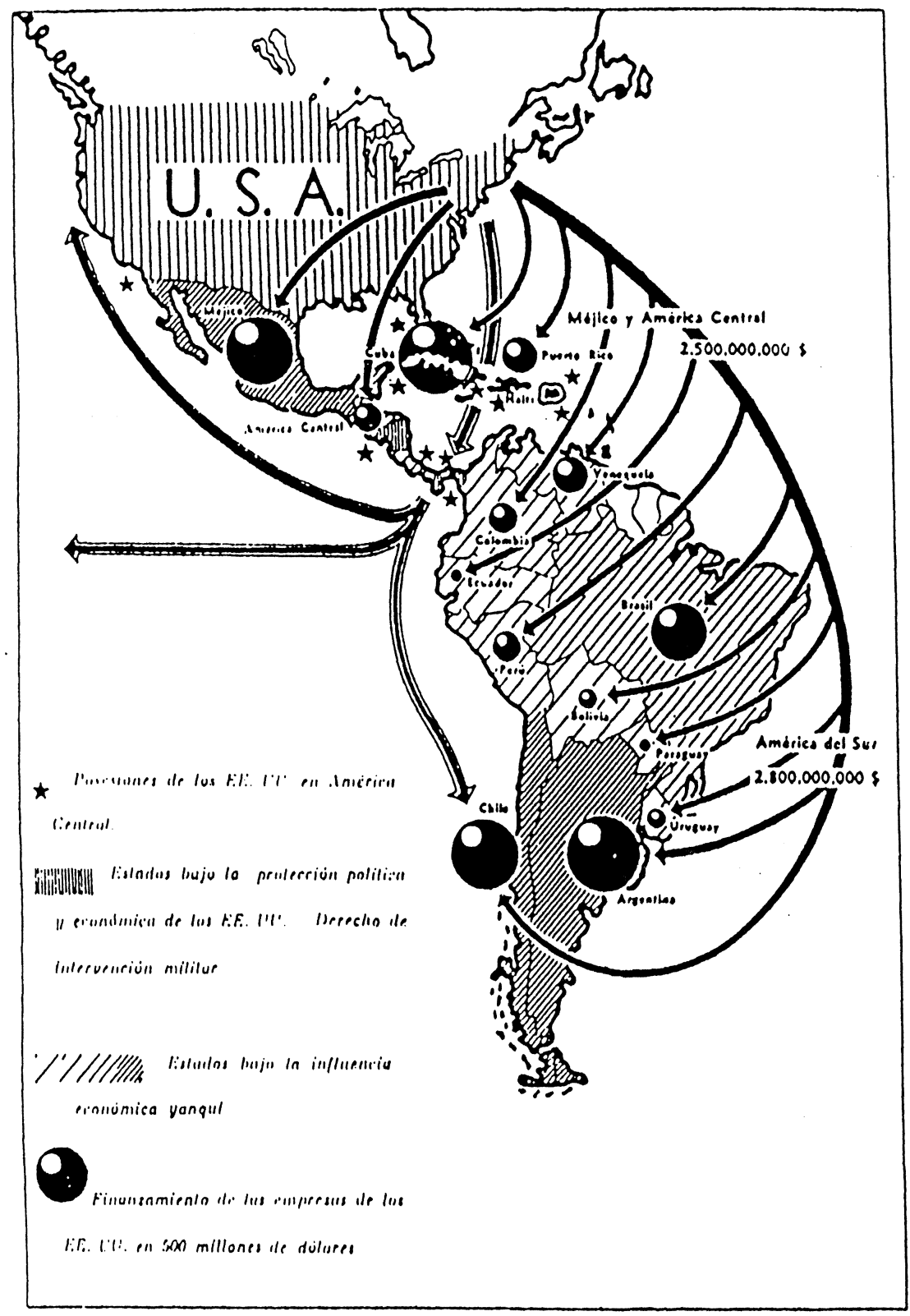

FIGURA 4.-El imperialismo del dólar (Vicens, 1940, p. 168). 


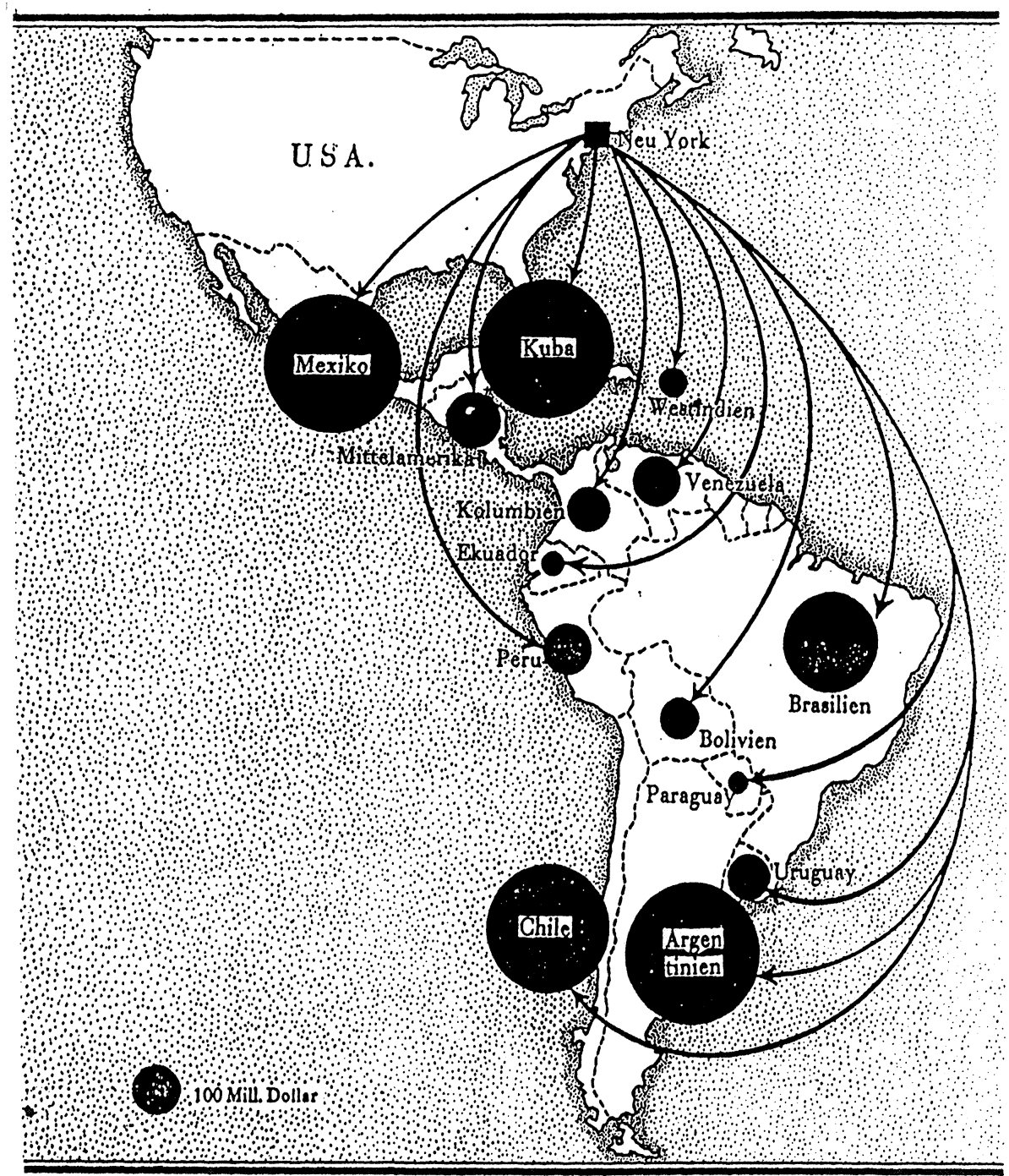

FIGURA 5.-El imperialismo del dólar (Jantzen, s.a., 1940, p. 8). 


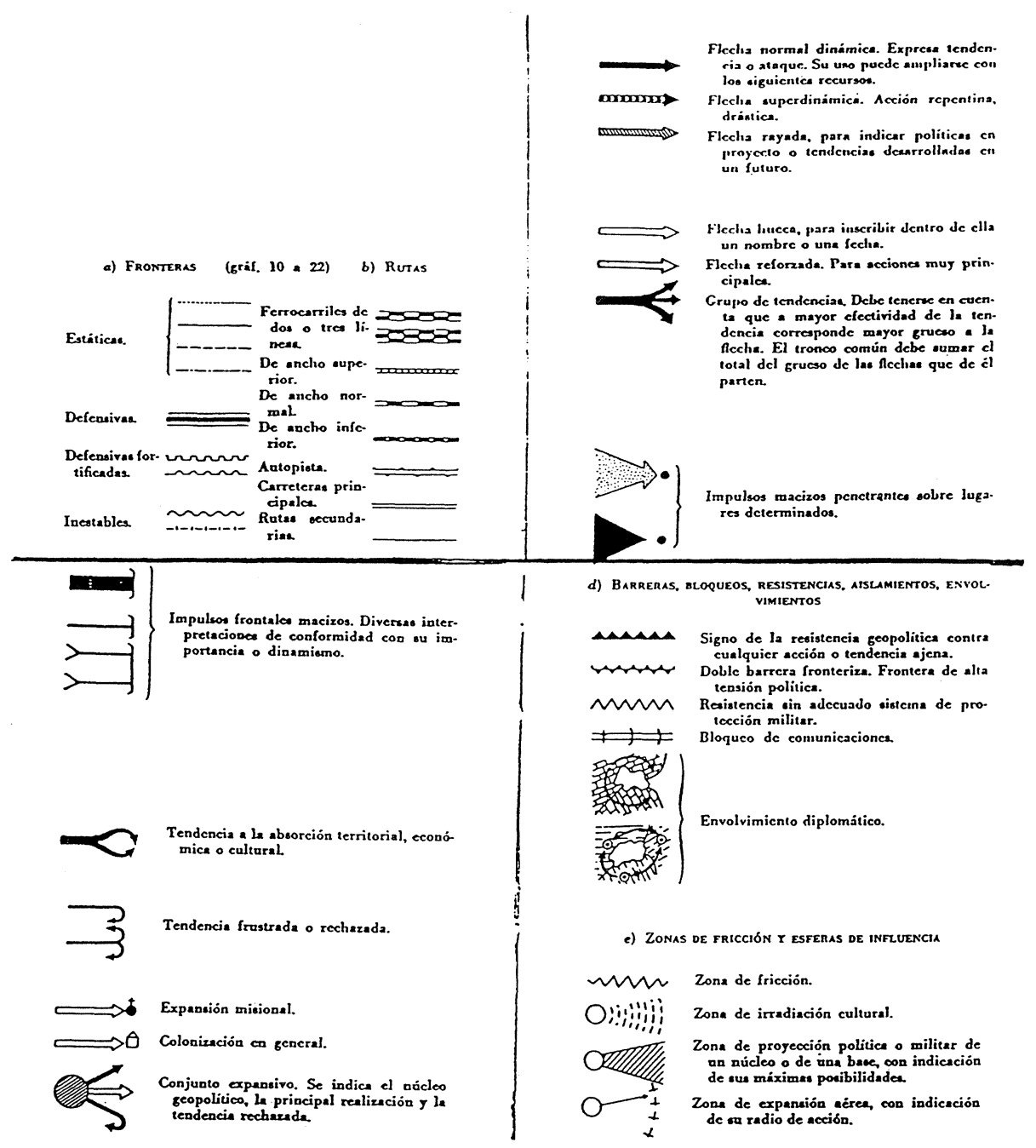

FIGURA 6.-Principales signos geopolíticos y geohistóricos

(Vicens, 1950, pp. 80-85). 

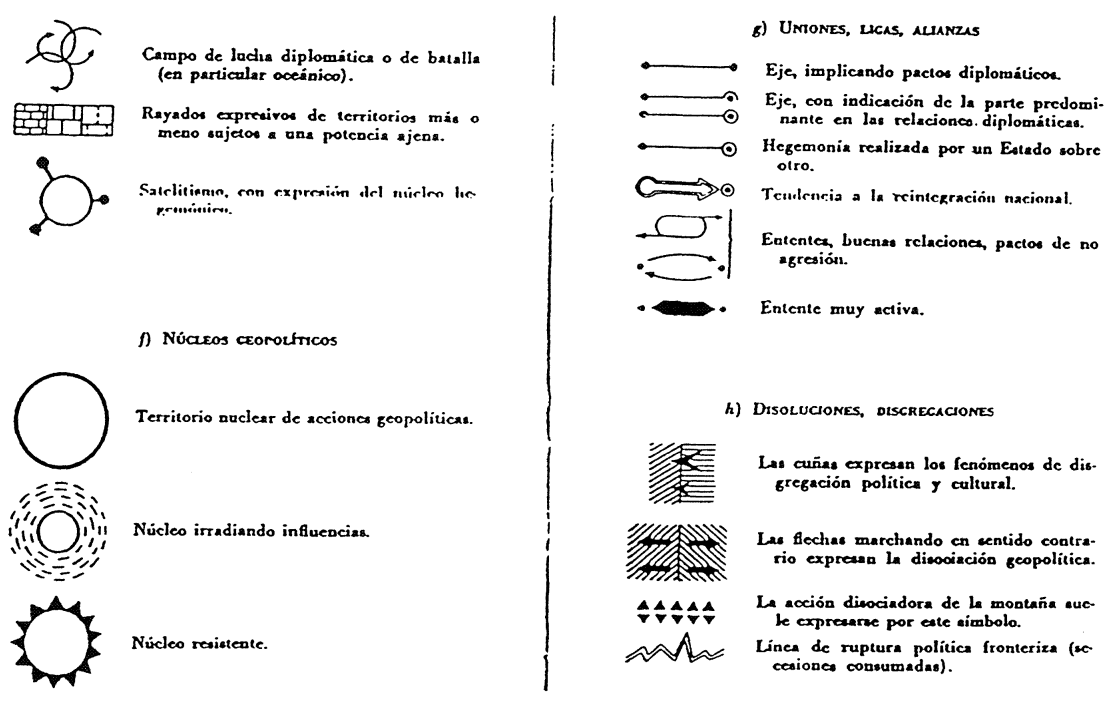

En relación a las características de los signos, plantea que no es obligado que se acomoden a las coordenadas geográficas, que sus únicas limitaciones han de ser «la realidad de su existencia y la intensidad de la acción geográfico-histórica a que responde» (Ibid.). Subraya su importancia al afirmar a continuación que el signo «puede y ha de predominar cuando lo requiera la inteligencia y la claridad del hecho geopolítico que se representa en el mapa» (Ibid.).

El carácter eminentemente introductorio de la obra le lleva a explicar la utilidad de los principales signos geopolíticos y a presentarlos: rayado y grafiado, flechas - del que afirma que es «el signo geopolítico por excelencia»-, línea recta, línea en zig-zag, círculo, triángulo y cuña (op. cit., pp. 24-25). Las mismas explicaciones, sin apenas modificaciones, las incluye en el Tratado General de Geopolítica (Vicens, 1950, p. 86).

Esta segunda obra - elaborada en una coyuntura política internacional y personal muy distinta - es completamente diferente. Vicens, a lo largo de sus páginas - además de matizar algunas ideas expuestas diez años antes-, señala los conceptos, principios y método de la geopolítica basándose en sus propios planteamientos, en las aportaciones 
de geógrafos y geopolitólogos alemanes (Ratzel, Obst, Maüll, etc.), franceses (Brunhes y Ancel) y anglosagones (Mackinder y Wittlesey), y en las de los historiadores Toynbee, Febvre y Braudel.

Muñoz i Lloret considera que el resultado de esta obra «es francamente decepcionante» $\mathrm{y}$, a pesar de reconocer su reedición en $1956{ }^{12}$, añade «es probablemente una de las obras menos logradas de Vicens y, con toda seguridad, una de las que más rápidamente ha envejecido... por que, en buena parte, ya nació sin vida» (Muñoz i Lloret, p. 197). Seguramente, desde una perspectiva historiográfica, que es la que sigue este autor en su tesis doctoral, puede extraerse esta noción, pero - sin entrar a valorar la utilidad y finalidad de la geopolítica, que en aquellos años, y en los siguientes, cayó en el más absoluto desprecio- puede afirmarse que es un auténtico «tratado» de la disciplina muy bien documentado y que, sin llegar a estructurar totalmente el cuerpo de la misma, aporta numerosas informaciones, valoraciones y consideraciones acerca de la misma. La obra sigue siendo empleada en ambientes geográficos universitarios que se dedican a estudiar la geopolítica.

En este volumen matiza opiniones vertidas en la obra anterior e insiste, desarrollándolos más ampliamente, en comentarios realizados en España. Geopolítica de..., tales como la validez de la cartografía geopolítica; las grandes aportaciones efectuadas por la escuela alemana; los peligros que pueden comportar los gráficos geopolíticos; la prudencia que debe de guiar el uso de los signos, de los que incluye una completa descripción de todo su repertorio (véase Fig. 6), etc.

En su deseo de resaltar el uso científico del símbolo geopolítico, declara que «todo signo deberá responder a una real concepción científica y amoldarse a las más claras normas cartográficas en cuanto a situación, dirección, distancia y limitación del símbolo geopolítico» (Vicens, 1950, p. 80). En este sentido, presenta ejemplos sobre su idea acerca de lo que debe ser un gráfico geopolítico correcto (véase Fig. 7). No obstante, y a pesar de recordar los citados consejos de Hillen Ziegfeld, no duda en incluir ciertos mapas de la escuela alemana. Entre ellos puede destacarse un mapa (véase Figs. 8, 9 y 10) extraído de un atlas de Jantzen en el que se acentúa «sugestivamente» la frontera económica de la Unión Soviética. Vicens podía haber optado por recoger el mapa de Braun y Hillen Ziegfeld — que también poseía- pero prefirió

${ }_{12}$ Posteriormente se realizaron otras ediciones. En 1981 se publicó la quinta. 


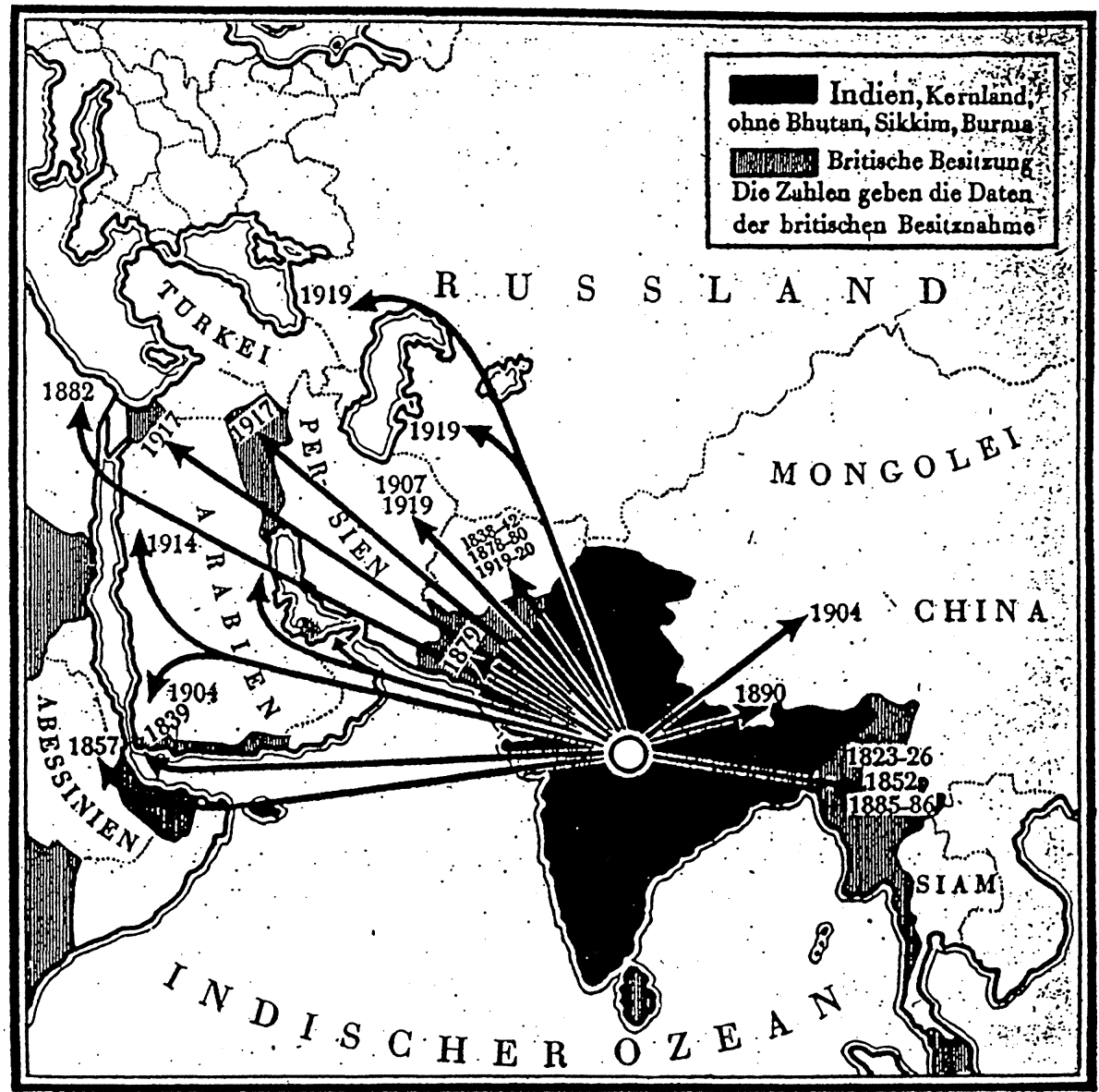

FigURA 7.-Un gráfico geopolítico: La protección de la India por Inglaterra (según Kohn) (Vicens, 1950, p. 79).

éste otro, mucho más impactante a causa de la utilización del color negro y el propio diseño de la frontera soviética. La elección, además, se encontraba muy en consonancia con el ambiente político oficial que imperaba en la España de aquellos años y con las ideas de Vicens respecto a los «regímenes comunistas».

Un último aspecto digno de mención es necesario comentar, aunque sea brevemente. En esta obra, Vicens presenta los «gráficos geohistó- 


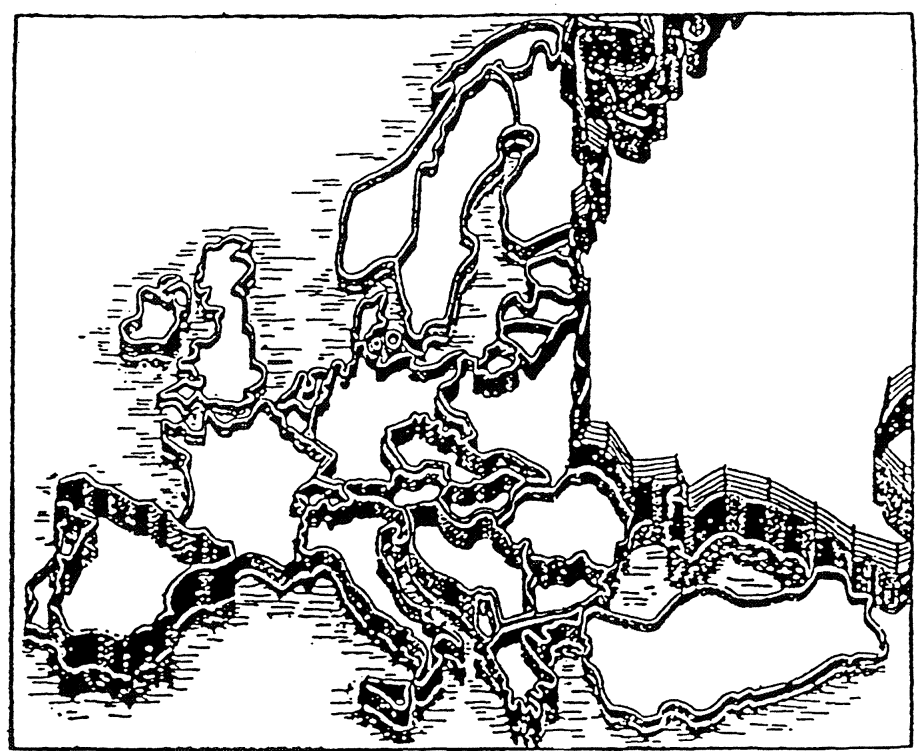

Una representación que causó sensación en Europa. El aparcelamiento económico del continente durante el periodo intermedio.

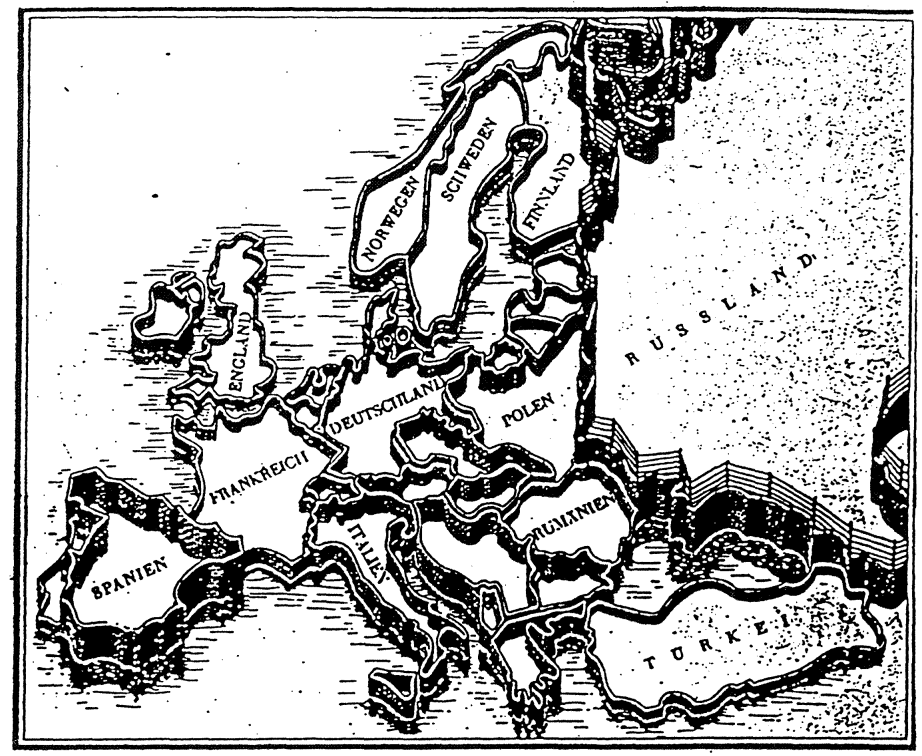

FiguRAS 8 y 9.-Fronteras geoeconómicas de Europa en 1934 (Vicens, 1950, p. 67, y Jantzen, 1941, p. 16). 


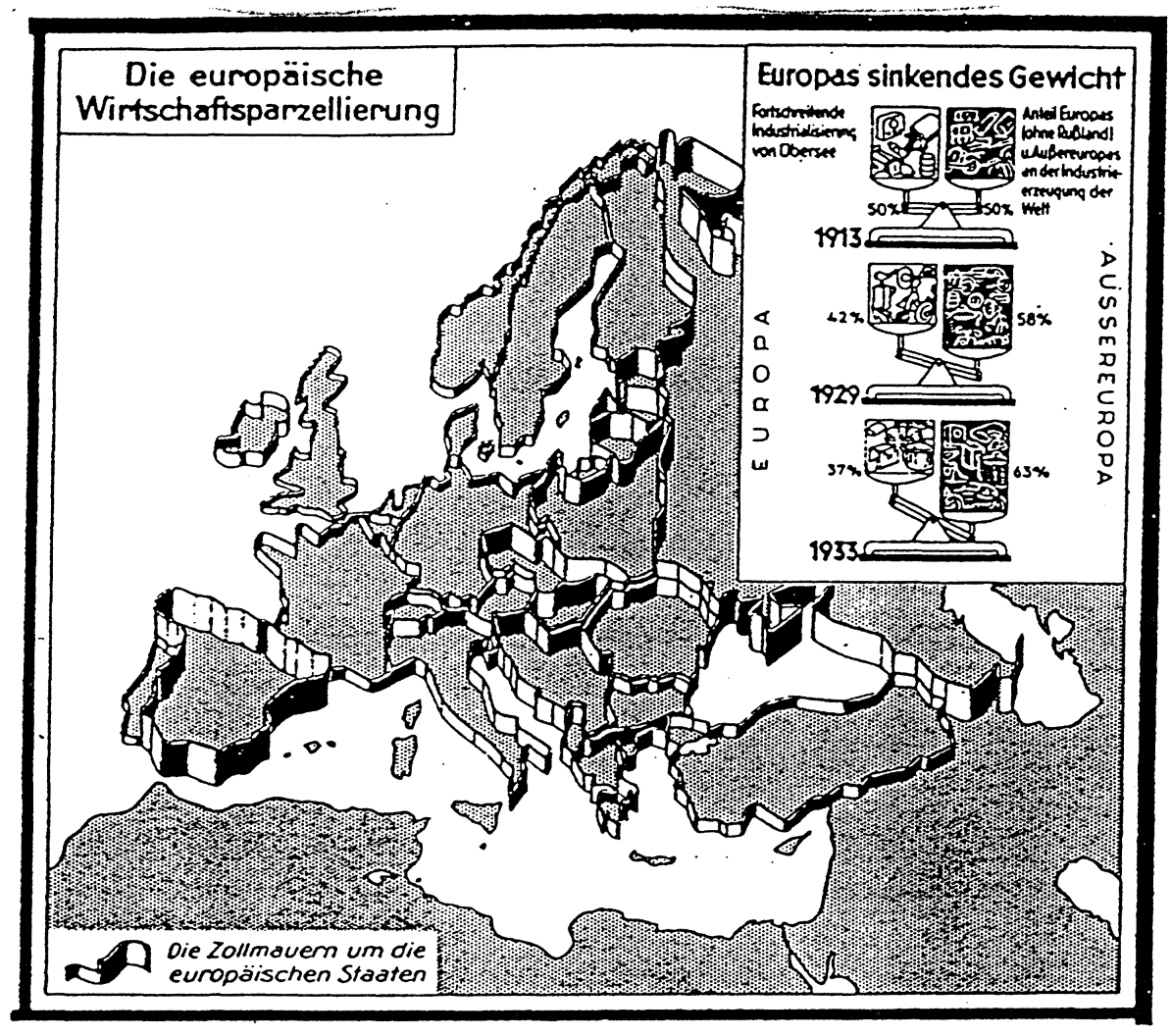

FIGURA 10.-Fronteras geoeconómicas en Europa (Braun y Hillen Ziegfeld, 1934, p. 56).

ricos» (véase Fig. 11), sobre los que recomienda su uso en la enseñanza universitaria, al permitir «expresiones mucho más abstractas, que incluso no necesitan una ubicación geográfica determinada (op. cit., p. 86). Estos gráficos, que sólo tienen valor esquemático, contienen «signos geopolíticos puros prescindiendo de su adaptación a las condiciones cartográficas reales» (Ibid.). 


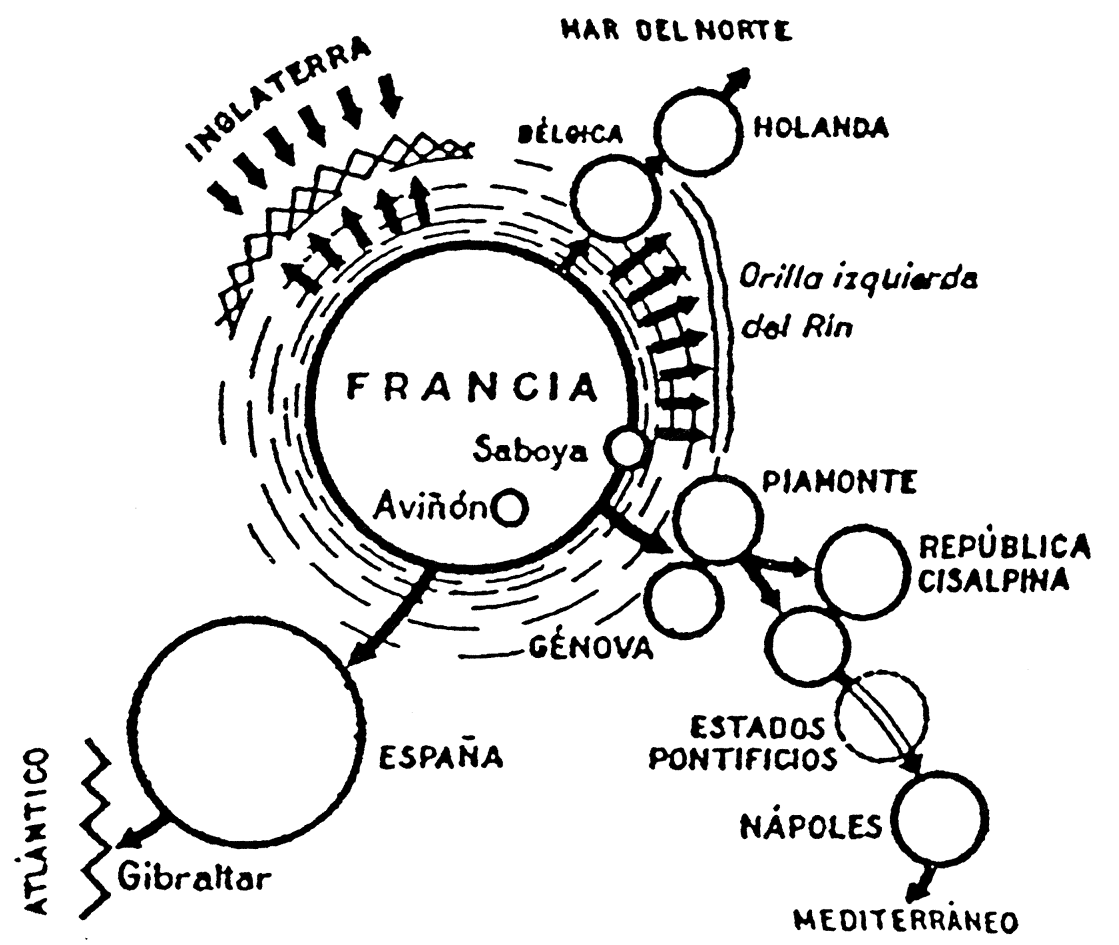

Figura 11.-La política francesa durante el Directorio (Vicens, 1950, p. 87).

\section{Conclusiones}

Vicens concedió una extraordinaria importancia a la cartografía en casi toda su obra. Mapas y gráficos se representan profusamente en sus publicaciones históricas, geográficas y geopolíticas, por los que pueden considerarse como elementos clave de su obra.

Su interés por la cartografía radicó, no sólo en la posibilidad que ofrece para situar acontecimientos históricos, sino también por la oportunidad que brinda para valorar correctamente la importancia y significación de los factores geográficos, así como su influencia en los primeros. Por otra parte le otorgó un papel fundamental, por su carácter sintético y pedagógico en sus labores educativas. En este ámbito, promovió continuamente el uso de mapas. Muestra de ello se encuentra 
en los atlas históricos y manuales de geografía e historia, destinados a la enseñanza secundaria, editados por Teide.

Su temprana preocupación por el tema nació de la lectura de $L a T e$ rre et l'évolution humaine de L. Febvre y del conocimiento que tuvo de las técnicas cartográficas utilizadas por la escuela alemana de geopolítica, que alcanzaron una gran difusión en la década de los años treinta. Una de las grandes aportaciones de Vicens en este ámbito fue la introducción en España de dichas técnicas.

La rigurosidad y cuidado que acompañaron su labor investigadora y educativa se plasmó igualmente en la seriedad con que encaró ciertos problemas metodológicos que presenta la cartografía, llegando a plantear principios normativos para la elaboración de mapas históricos. Pero, en el aspecto que manifestó con mayor intensidad este tipo de preocupaciones, fue cuando trabajó con mapas geopolíticos. Ante la peligrosa capacidad «sugestiva» que éstos encerraban, insistió en el correcto uso científico de los signos geopolíticos, alejando de cualquier intencionalidad propagandística y tergiversadora. A pesar de ello, en determinados momentos de su vida, se vio «deslumbrado» por las técnicas cartográficas de la escuela alemana y publicó algunos mapas «un tanto sugestivos».

\section{BIBLIOGRAFÍA}

Batalle i TREmoleda, D. y Rabella i Vives, J. M.: «La Geografía vista per un historiador», Revista de Girona, n. ${ }^{\circ}$ 84, 1978, pp. 281-287.

Bosque MAurel, J.; Bosque Sendra, J. y García Ballesteros, A.: «Geografía política y geografía militar en España (1940-1983), III Coloquio Ibérico de Geografía. Actas. Ponencias y Comunicaciones, Barcelona, 1984, Universidad de Barcelona, pp. 45-55.

Braun, F. y Hillen Ziegfeld, A.: Geopolitischer Geschichsatlas, Dresden, 1934, Verlag von L. Ehlermann, $64 \mathrm{p}$.

CiricI, A.: A cor batent, Barcelona, 1976, Destino, $237 \mathrm{p}$.

Fabre, A. y Villanova, J. L.: «Jaume Vicens Vives. 1910-1960», Geographers. Biobibliographical Studies, vol. 17, 1997, pp. 92-105.

Galera, P.: «Publicaciones de Vicens Vives», en Maluquer de Motes, J. (ed.), Homenaje a Jaime Vicens Vives, vol. 1, Barcelona, 1965, Universidad de Barcelona, pp. XIXXXXV.

HAUSHOFER, K.: Jenseits der Grossmätche, Leipzig und Berlin, 1932, Verlag und Druck von B. G., Teubner, $520 \mathrm{p}$.

JANTZEN, W.: Geopolitik im Kartenbild. Seegeltum, Heidelberg, S. A., Kurt Vowinckel Verlag, $16 \mathrm{p}$.

—: Geopolitisches zur Weltlage, Heidelberg, 1941, Kurt Vowinckel Verlag, 16 p. 
Joseph I MAYOL, M.: El salvament del patrimoni artístic català durant la guerra civil, Barcelona, 1971, Pòrtic, $163 \mathrm{p}$.

MuÑoz I LloRET, J. M.: Jaume Vicens Vives. Una biografía intel.lectual, Barcelona, 1997, Ed. 62, 419 p.

Reguera Rodríguez, A. T.: «Fascismo y geopolítica en España», Geocrítica, n. 94 (monográfico), $63 \mathrm{p}$.

VICENS VIVES, J.: «Las ambiciones territoriales de la Rusia roja. La U.R.S.S., El Báltico y el mar libre», Destino, n. ${ }^{\circ} 125,1939$, p. 4. (Seud.: Lorenzo Guillen.)

-: España. Geopolítica del Estado y del Imperio, Barcelona, 1940, Yunque, 215 p.

—: Tratado general de Geopolítica, Barcelona, 1950, Teide, $242 \mathrm{p}$.

—: «L. Febvre y los "Annales"», Destino, n. ${ }^{\circ} 708,1951$, p. 14.

—: Atlas de historia de España, Barcelona, 1953, Teide, 144 p. (4. ${ }^{\mathrm{a}}$ ed. -renovada y $1 .^{\mathrm{a}}$ en color- del Atlas y síntesis de historia de España, Barcelona, 1944, Teide. Consultada la 8. ${ }^{a}$ ed. publicada en 1973.)

—: Atlas de historia universal, Barcelona, 1957, Teide, 134 p. (3. ${ }^{\text {a }}$ ed. - ampliada, renovada y $2 .^{a}$ en color- del Atlas y síntesis de historia universal, Barcelona, 1945, Teide. Consultada la 17. ${ }^{a}$ ed. publicada en 1982.)

Vicens VIVES, J. y SobReques VIDAL, S.: España geográfica. Curso de geografía, Barcelona, 1959, Teide, $242 \mathrm{p}$. (Consultada la $8 .^{\mathrm{a}}$ ed. publicada en 1966.)

VILlanOVA, J. L.: «Jaume Vicens Vives i l'estudi de la geopolítica», Revista de Girona, n. ${ }^{\circ} 171,1995$, pp. $52-55$.

WOLFF, PH. y VICENS, J.: «Principios de un método para la elaboración de los mapas históricos de un atlas pirenaico», Actas del Primer Congreso Internacional de Pireneistas, San Sebastián, 1950. (Consultada separata, publicada en 1950 en Zaragoza por el C.S.I.C., 12 p.)

RESUMEN: En este artículo se realiza un análisis introductorio de los planteamientos del historiador Jaume Vicens Vives sobre la cartografía, a la que concedió extraordinaria importancia en su vida profesional y que puede considerarse un elemento clave de su obra. Se estudian el origen de este interés, sus ideas, fuentes utilizadas, aportaciones, estructura de algunos de sus trabajos y el papel que otorgó a la cartografía en el conjunto de su obra histórica, geográfica y geopolítica, tanto a nivel académico como divulgativo y educativo. Entre sus aportaciones cabe destecar que fue el introductor en España de los principios y técnicas cartográficas de la escuela alemana de geopolítica.

PalabRas Clave: Vicens Vives, cartografía, geopolítica.

ABSTRACT: This article is an introductory analysis about the expositions of the historian Jaume Vicens Vives relating to cartography to which he attached great importance in his professional life. Cartography can be considered a key subject of his work. As well as the role he gave to cartography in his whole work dealing with History, Geography and Geopolitics, it is also studied here the origin of his interest, ideas, source, contributions and structure concerning to some of his work and not only in academic way but educative and popularization too. Among his contributions it is remarcable that he was the introducer of Geopolitical German School cartographical principles and method into Spain.

KEY wORDS: Vicens Vives, cartography, geopolitics. 
RÉSUMÉ: Dans ce article on réalise une analyse d'introduction aux idées de l'historien Jaume Vicens Vives sur la cartographie. Vicens concéda une extraordinaire importance, dans sa vie professionelle, à la cartographie et on peut la considérer un élement clé de ses travaux. On y étudient l'origine de son intêrest, ses idées, les fonts utilisées, ses apports, la structure de certains de ses travaux et le rôle que Vicens attribua à la cartographie dans l'ensemble de son ouvrage historique, géographique et géopolitique, au niveau universitaire, éducatif et de divulgation. Parmi ses apports, on peut souligner que Vicens fut l'introducteur en Espagne des principes et techniques cartographiques de l'école allemande de géopolitique.

MoTS CLÉS: Vicens Vives, cartographie, géopolitique. 